\title{
Message from the 2014 Program Chair
}

\author{
Gregory S. Smith
}

Published online: 18 November 2014

(C) International Association of Medical Science Educators 2014

It is our privilege to present to you the conference proceedings from the 18th annual meeting of the International Association of Medical Science Educators (IAMSE), held in beautiful Nashville Tennessee in June 2014. More than 400 attendees from 20 countries and 42 US states met for 4 days in this dynamic university town.

The program committee designed the meeting to focus on the premise that the transforming landscape of medical education has created an unprecedented opportunity for medical educators to write the script for the future of medical education. The 2014 program sessions addressed a variety of related topics including technology, providing effective feedback, assessment approaches, simulation, appreciative inquiry, interprofessional education, and other contemporary topics. Notably, the Saturday preconference workshops featured over 85 meeting attendees to discuss continuous integration of basic science and clinical medicine, strategies on how to make active learning more effective, teaching ultrasound, applying adult learning theory, and how to overcome various barriers to publication.

Five distinguished speakers presented key topics in contemporary medical sciences education. David Pederson delivered an address on the use of simulation, robotic surgery, technology, and ultrasound to engage tomorrow's physicians. Mavis Schorn and colleagues discussed the use of Interprofessional Education (IPE) at Vanderbilt and interestingly described the application of IPE between Vanderbilt students and students from other universities as well. Nikki Woods gave a presentation on how physicians use foundational sciences to assist in their clinical reasoning and decision making. Karen Cornell addressed the importance of providing effective feedback to students and colleagues, stressing the importance of good communication skills and how to handle difficult conversations. Lastly, John Pelley closed out our meeting with a presentation on new ways to engage students outside of didactic lectures by creating novel and effective active learning strategies.

Continuing a long standing IAMSE tradition, meeting attendees were offered the opportunity to participate actively in topics garnered from 36 focus sessions and had the opportunity to interact with fellow educators through various poster sessions.

In this special issue of Medical Science Educator, we share with you the abstracts of the posters and e-demos. We also present to you a short innovation article of the 2014 Poster Award winners. We hope you will be as inspired reading these contributions as we were to witness them in person. Please join us in our next annual meeting on June 7-10, 2015 in San Diego, CA, USA. We look forward to seeing you there!

Gregory S. Smith, Ph.D.

Chair, 2014 Program Planning Committee

G. S. Smith $(\bowtie)$

Saint Louis University, St Louis, MO, USA

e-mail: smithp2@slu.edu 